\title{
Gastos Públicos e Crescimento Econômico: um Recorte para Pernambuco entre de 2008 e 2015
}

Public Expending and Economic Growth: An Analysis for Pernambuco between 2008 and 2015

\author{
João Erick Alexandre Barbosa Costa ${ }^{a}$ \\ Sonia Rebouças da Silva Melob \\ Monaliza de Oliveira Ferreirac
}

\begin{abstract}
Resumo: O objetivo do trabalho consiste em analisar a relação entre as variáveis que compõem os dispêndios públicos e o PIB dos munícipios pernambucanos nos anos de 2008 a 2015. O modelo estimado utilizou um painel de Efeitos Fixos, com dados sobre gastos per capita em nível municipal do Estado de Pernambuco em educação, cultura, saúde e saneamento. Em linhas gerais, conclui-se que os gastos per capita em educação mostraram-se diretamente relacionados com o crescimento econômico, corroborando estudos anteriores apontados na literatura nacional. Mas não houve relação positiva entre o produto interno e variáveis como saúde, saneamento, habitação e urbanismo. Diferenças regionais entre as unidades federativas de país continental e questões institucionais podem justificar tais resultados.
\end{abstract}

Palavras-chave: Crescimento Econômico; Gastos Públicos; Municípios; Pernambuco. Classificação JEL: H30, H50, H70.

\begin{abstract}
The purpose of this work consists in analyzing the relation between the variables which comprise public expenditure and the GDP of the cities in Pernambuco through the years 2008 to 2015. The estimated model used a Fixed Effects panel, with per capita data at the municipal level in the Pernambuco State in relation to education, culture, health care, and sanitation. In general, it can be concluded that the per capita expenditure in education was directly related to economic growth, corroborating previous studies found in the national literature. However, there was no positive relation between GDP and variables such as health care, sanitation, public housing, and urbanism. Regional differences between federative units in a continental country, and institutional issues, may justify these results.
\end{abstract}

Keywords: Economic Growth; Public Spending; Municipalities; Pernambuco.

\footnotetext{
${ }^{\text {a }}$ Mestrando em Economia no Programa de Pós-Graduação em Economia - NUPEC/UFS.

E-mail: erickalexandre239790@gmail.com.

b Docente do Núcleo de Gestão/UFPE. E-mail: soniareboucas@gmail.com.

${ }^{c}$ Docente do Programa de Pós-Graduação em Economia - PPGECON/UFPE.

E-mail: monaliza.ferreira@ufpe.br.
} 


\section{Introdução}

A atenção com os efeitos dos gastos públicos pelos pesquisadores é frequente, especialmente no que diz respeito aos efeitos sobre o crescimento econômico. Muitas pesquisas teóricas e empíricas apontam que esses gastos podem proporcionar um aumento no crescimento econômico de uma determinada economia e, também, podem aumentar a produtividade do setor privado (Cândido Júnior, 2001).

É de conhecimento geral também que gastos públicos em educação, saúde, estradas e energia são fatores de impacto positivo no capital humano e físico de um país, o que acarreta aumento de renda per capita e da produtividade total dos fatores. Ademais, segundo destacam Cruz, Teixeira e Braga (2010), gastos nestas categorias geram crescimento econômico com redução da pobreza. Mas a literatura também tem revelado que municípios mais pobres necessitam gastar mais para alcançar o crescimento com redução de pobreza (Divino e Silva Júnior, 2012). Por outro lado, Bender Filho (2019) chama a atenção de que a expansão dos gastos por si só não seria condição suficiente para alavancar crescimento econômico. Isto só aconteceria priorizando investimentos que tivessem efeitos sobre a demanda agregada.

Na verdade, existe heterogeneidade nos efeitos dos gastos dos diferentes países, uma vez que estes possuem sistemas econômicos distintos, de forma que diferentes graus de incerteza fiscal, em níveis comparáveis de dívida pública entre esses sistemas econômicos, constituem uma importante fonte de heterogeneidade na relação de gastos públicos e PIB. Alguns países enfrentam mais crescimento, reduzindo os efeitos da dívida pública mais do que outros, podendo os gastos exercerem efeitos neutros, positivos ou negativos sobre o produto interno (Ahlborn e Schweickert, 2016; Beckmann, Endrich e Schweickert, 2016).

Por outro lado, como os gastos públicos dependem da arrecadação tributária, convém destacar que um nível mais alto de qualidade institucional reforça a percepção positiva da qualidade dos serviços públicos. Então, não é o tamanho do setor público, definido a depender de o país ser mais rico ou mais pobre, que define necessariamente a qualidade da arrecadação tributária, mas a qualidade institucional que leva à eficácia do governo em ofertar bens públicos de qualidade, gerando efeitos positivos sobre a arrecadação tributária (Arora e Chong, 2018).

Esta discussão da eficiência de gastos públicos não é de hoje e intensificou-se na década de 2010, quando a literatura já indicava que a eficácia do governo determina o impacto do gasto público no crescimento econômico. Países desenvolvidos e menos desenvolvidos não teriam a mesma necessidade de investimentos, de forma que estes últimos poderiam priorizar, num primeiro momento, gastos em infraestrutura ao invés de gastos em consumo, por exemplo (Butkiewicz e Yanikkaya, 2011).

Nesse contexto, alguns estudos têm reexaminado a validade da lei de Wagner, segundo a qual o desenvolvimento econômico é o principal determinante para o crescimento do setor público. Esses estudos têm revelado que o setor público cresce proporcionalmente em relação às rendas nacionais (Paparas, Richter e Kostakis, 2018). 
A nova teoria do crescimento - ou teoria do crescimento endógeno - substituiu os retornos decrescentes da suposição de capital pelos retornos crescentes do capital humano e abandonou a suposição exógena de progresso técnico. A esse respeito, a teoria do crescimento endógeno se aproxima do paradigma keynesiano de que os fatores de entrada são endógenos e determinados pela força da demanda. Embora a nova teoria do crescimento reconheça a natureza endógena do crescimento do produto, ela não considera explicitamente que o crescimento possa ser limitado à balança de pagamentos. Todavia, destaca que a política mais eficiente para alcançar um crescimento mais alto seria reduzir os desequilíbrios externos (Soukiazis, Antunes e Kostakis, 2017).

Paralelamente a esta discussão mais macroeconômica, uma geração de políticas em relação aos gastos públicos regionais vem se destacando desde os anos 1980 no Brasil. Passando por um procedimento de descentralização fiscal, especialmente após a publicação da Constituição Federal de 1988, que promoveu maior independência aos Governos estaduais e municipais. Na Constituição de 1988, o governo central teve que renunciar parte do seu controle a respeito da política fiscal, verificando-se assim um antagonismo entre políticas de provisão de bens e serviços e políticas macroeconômicas, advindos em grande maioria dos governos estaduais e municipais (Macedo e Corbari, 2009).

Muitos programas foram executados com a intenção de propiciar crescimento e desenvolvimento para regiões mais carentes, como é o exemplo do uso de incentivos fiscais oferecidos pela Superintendência do Desenvolvimento do Nordeste (SUDENE). Já na esfera municipal do Estado de Pernambuco, há uma execução de gastos nas áreas da educação, cultura, saúde, saneamento básico, urbanização, habitação e em várias outras áreas na intenção de sanar as diferenças regionais existentes dentro da economia do Estado.

No que tange à política de gastos e atração de investimentos praticadas pelos governos dos municípios de Pernambuco, esta se mostra bastante próxima à teoria keynesiana, visto que se debruça na intervenção estatal para alcançar o crescimento. Sendo elas, a atração de investimentos, onde o governo estadual junto aos governos municipais está fazendo uso de uma série de medidas que vão desde a autorização de benefícios específicos às empresas que se inserem nos municípios do Estado, como também a concessão de reduções tributárias (Frota, 2013).

Assim, o objetivo deste estudo consiste em averiguar a relação entre gastos públicos e crescimento econômico nos municípios pernambucanos no período de 2008 a 2015. Para tal, este estudo está embasado nas hipóteses evidenciadas no modelo proposto por Bogoni, Hein, Beuren (2011) e Barros (2013), onde os gastos públicos são condições essenciais para a promoção de um crescimento econômico sustentável, tendo um governo que realize gastos num ponto eficiente. Além disso, a presente pesquisa caracteriza-se de natureza descritiva, com método quantitativo e de dados em painel.

Além desta seção introdutória, as próximas seções tratam da revisão de literatura, com discussões voltadas para gastos públicos e crescimento econômico, e gastos públicos em educação, saúde e saneamento. Na sequência, são descritas as variáveis e método de análise. Posteriormente, são apresentados os resultados e discussão do estudo e, por fïm, as considerações finais. 


\section{Gastos Públicos e Crescimento Econômico}

A sociedade espera a melhor utilização dos recursos públicos, uma vez que existe um teto que limita a expansão das receitas que financiam o crescimento dos gastos. E levando em consideração a predisposição de o crescimento ocorrer de forma diferente nas diversas economias e regiões, assinala-se a necessidade das políticas públicas na área de gastos públicos como uma maneira de amenizar os efeitos perversos ocasionado por esse processo desigual. Neste sentido, segundo Frota (2013), os incentivos fiscais têm como característica principal de captar investimentos para determinadas regiões e, com isso, proporcionar um crescimento regional. Para o alcance deste cenário, é dada a isenção de alguns impostos e garantias de redução de alguns tributos.

Ao levar em consideração os efeitos de políticas públicas de gastos influenciando o crescimento econômico num ponto eficiente, pode-se considerar dois argumentos. O primeiro indica que uma alta cobrança de impostos, juntamente à alocação ineficiente dos recursos públicos, corrobora para um crescimento econômico cheio de obstáculos e gargalos. Em contrapartida, uma perspectiva diferente pode conceituar um postulado central de um crescimento sustentável, no qual insere pelo aperfeiçoamento do fornecimento de bens públicos que se constitui em externalidades positivas sobre o nível da atividade econômica ao incentivar o investimento, fornecendo assim uma conjuntura ótima de tendência ao crescimento econômico de uma economia (Arraes e Teles, 2001).

Matias-Pereira (2009) observa que o Estado deve prover oferta de serviços, garantia de direitos e distribuição de recursos. O setor público impacta de maneira efetiva no cotidiano dos agentes sociais e econômicos, pois o Estado tem como função fundamental promover o bem-comum na sociedade, tomando medidas e/ou decisões para atender as necessidades públicas da nação. E ainda, afirma que a abordagem da administração pública é muito relevante ao determinar os conceitos de eficácia, eficiência e efetividade quanto aos gastos públicos. Por fim, aponta que eficiência se refere à execução com o qual realizam-se as ações pretendidas pelo governo. Já eficácia diz respeito ao resultado da ação desejada e a efetividade condiz com o grau de qualidade obtido do resultado.

Nas palavras de Teixeira e Barroso (2003), há uma preocupação dos gestores públicos em verificar se há eficácia e eficiência dos gastos públicos executados pelo governo. Como existem limitações orçamentárias, é de importância para a sociedade e dever dos gestores públicos que, respeitando os métodos adequados, os recursos disponíveis e as características de cada localidade, o sistema público funcione com eficiência máxima, de modo que seja fornecida uma quantidade ótima de insumos em produtos e serviços oferecidos à população como promoção de crescimento sustentável. A destinação de recursos públicos é um dos obstáculos enfrentados diariamente pela nação, pela importância que os gastos públicos possuem para todos os cidadãos. Daí a relevância de que a destinação dos recursos possa proporcionar o máximo de benefício social.

Neste sentido, a partir dos anos 2000 ocorreram alguns movimentos com a globalização, sendo um deles o surgimento de leis que instituíram uma maior transparência na prestação das contas públicas. Por exemplo, a publicação da Lei Complementar $\mathrm{n}^{\circ} 101$, 
de 4 de maio de 2000 (Lei de Responsabilidade Fiscal - LRF) exigiu do setor público que a política fiscal em relação aos gastos públicos seja executada da melhor forma.

Portanto, a análise de gastos públicos e programas governamentais ganhou destaque para as atribuições de planejamento e gestão, pois se mostra como um mecanismo para a promoção de eficiência dos gastos públicos, da qualidade da gestão e para a divulgação dos feitos do governo. Assim, há um interesse dos governantes por pesquisas que evidenciem que os gastos públicos são promotores de crescimento econômico, sendo esta uma ideia relacionada à competência informacional para os implementadores e gestores de políticas públicas no sentido de otimizar os gastos públicos (Cunha, 2006).

No caso do Brasil, grande parte dos estudos concentram-se nos efeitos dos gastos agregados sobre o crescimento ou no impacto de alguma variável sobre o crescimento econômico. Como indicam Correia e Neduziak (2017), os gastos públicos no Brasil se apresentam com uma expressiva mudança ao longo do tempo entre os entes federativos. A correlação com gastos em educação/gastos correntes caiu na significância dos $21 \%$ no ano de 1997 para 16\% em 2001, ao mesmo tempo que a razão de gastos em saúde e saneamento/gastos correntes elevou-se da casa dos 8\% no ano de 1995 para 13\% em 2011. Como descrito anteriormente, muitos desses acontecimentos fiscais ocorreram na economia brasileira, tal como a LRF, que determinou regras e impôs uma restrição orçamentária em relação à expansão dos gastos do governo. Assim, os autores buscaram analisar o impacto dos gastos públicos em relação à taxa de crescimento das unidades de federação do Brasil no período de 1995-2011. Por fim, eles destacam que gastos públicos em investimento, quando bem aplicados, podem influenciar positivamente no crescimento econômico de longo prazo do país, independentemente do órgão de análise, se federal, estadual ou municipal.

Nessa perspectiva, Cândido Júnior (2001) analisou a relação empírica entre gastos públicos e crescimento econômico no Brasil, no período de 1947-1995. À guisa de conclusão, o autor destacou dois canais de transmissão do gasto público para o meio privado: (i) os dispêndios em infraestrutura, educação e saúde, impactam efetivamente o uso de capital físico e mão de obra privada (além das leis e segurança nacional que afetam, de forma indireta, o âmbito onde são tomadas as decisões); e (ii) o impacto dos gastos púbicos agregados sobre o crescimento econômico quando atingido um teto ótimo, apontando para significativas evidências de baixa produtividade a partir de certo teto. Esse resultado já era de se presumir, pois há limitações na relação das receitas que financiam os gastos, onde a produtividade do dispêndio público não cresce a partir de limites das receitas, consequentemente levando a uma diminuição do PIB.

Rodrigues e Teixeira (2010) analisaram qual dos gastos mais impactaram o crescimento econômico brasileiro, durante os anos de 1948-1998: (a) consumo, (b) subsídios e (c) transferências. A conclusão mostra que estados e os governos municipais foram os que mais influenciaram a trajetória do crescimento econômico, sendo o investimento a variável de maior importância do estudo. Por outro lado, os gastos de ordem de consumo, subsídios e transferências devem ser analisados com mais robustez, uma vez que a esfera pública é pouca produtiva no manejo dessas variáveis. 
Ainda considerando essa visão, Silva e Triches (2014) analisaram a influência dos gastos públicos sobre o produto, nos anos de 1980-2005, onde foram consideradas despesas produtivas os gastos em comunicação, transporte e saneamento. Observaram que essas variáveis se apresentaram bastante significativas do ponto de vista estatístico, bem como os gastos públicos destinados às áreas de infraestrutura de transporte, saúde e saneamento básico se revelaram como fatores que influenciam positivamente o crescimento econômico do PIB.

Rocha e Giubert (2007) e Divino e Silva Jr. (2012) analisaram os efeitos de gastos públicos influenciando o crescimento econômico, mas a análise dá-se no âmbito dos municípios brasileiros. Eles concluíram que os gastos públicos agregados impactam positivamente o crescimento econômico dos municípios. Além disto, destacaram que a renda inicial, a desigualdade de renda e o número de homicídios evidenciaram-se como efeito cruel sobre a taxa de crescimento do PIB. Em matéria de gastos, para municípios abaixo da linha da pobreza, os gastos correntes mostraram-se produtivos em detrimento do gasto de capital. Essa conclusão pode estar relacionada ao fato de que os gastos nessa área, influenciando o crescimento econômico, mostrarem-se primordiais para economias mais pobres.

Já em relação ao Estado de Pernambuco, Barros (2013) afirmou que embora o Estado se apresentasse como a região mais desenvolvida da Região Nordeste, a nível nacional ainda mostrava desigualdades pertinentes com relação às grandes economias do Sudeste e Sul. Entretanto, o mesmo estudo afirma que nos últimos anos analisados o Governo teria adotado medidas de políticas de atração de investimentos e reestruturação, de forma que o sucesso dessas medidas poderia possivelmente trazer possibilidades de crescimento econômico para vários municípios. Os gastos públicos com educação e cultura, habitação e urbanização tiveram influência positiva sobre a produção interna bruta dos municípios de Pernambuco. Além disso, a pesquisa analisou que existia um nível de desigualdade muito expressivo entre os municípios, de maneira que a Região Metropolitana retinha a maior parte da produção interna bruta, ao mesmo tempo que as outras regiões apresentavam um nível de produção pouco expressivo.

Há uma gama de estudos que discutem a relação existente entre tamanho do governo e crescimento econômico. Assim, é importante discutir sobre a composição dos gastos públicos influenciando a taxa de crescimento de uma economia através da composição dos seus gastos, havendo, portanto, duas explicações. A primeira é em relação ao tamanho do Governo, que é uma decisão de escolha pública sua composição, sendo este um instrumento político. A diferença entre gastos produtivos e improdutivos e a formação de como o País pode aprimorar seu desempenho econômico, transformando a junção entre os dois, pode possivelmente melhorar na adequação do uso desse instrumento. Já a segunda é em relação aos ajustes fiscais, no qual, encara-se a difícil escolha de onde fazer cortes fiscais suplementares. Então, tem-se a indagação de qual componente dos gastos públicos deve ser desagregado. A solução possivelmente será, dentre outras, a contribuição em que cada um dos componentes do gasto proporciona para o crescimento econômico (Rocha e Giuberti, 2007). 
De acordo com Riani (2002), a composição dos gastos públicos abrange o somatório de todos gastos governamentais com a administração (direta e indireta) mais os custeios com exercícios econômicos produtivos do governo. Essa composição é orçada de acordo com sua finalidade, natureza e função. Por haver um grande grau de detalhamento das informações, a composição dos gastos públicos apresentada pela administração direta e indireta poder ser categorizada em grandes agregados, categorias e/ou funções.

Rezende (2001) afirma que essas composições podem ser classificadas atendendo suas especificidades de acordo com o agente encarregado de executar os gastos. Feito isto, ela é considerada em funções, programas, projetos, entre outros. Com relação à função dos gastos, estes podem ser classificados em quatro categorias: custeio, investimento, transferências e inversões financeiras. Tal ordenamento evidencia como são alocados os recursos públicos em diversos setores, tais como saúde, assistência social, administração, educação, saneamento, urbanismo, infraestrutura, transporte e entre outros.

Portanto, o setor público precisa viabilizar a oferta de bens e serviços para atender as necessidades da sociedade, compreendendo a importância de acumular capital para atender necessidades futuras da população. Como o Estado possui um teto orçamentário, isto promove a substituição entre gastos correntes e gastos de capital. Assim, os formuladores de políticas públicas devem escolher uma composição ideal de gastos para atingir os efeitos máximos da política fiscal. E um dos mecanismos que o governo tem à sua disponibilidade é a política fiscal, que pode ser usada em gastos correntes e também em gastos de capital. Na primeira situação, elencam-se os gastos com educação, saúde, segurança e distribuição de renda, enquanto no segundo caso configuram-se despesas com infraestrutura, comunicação e transporte. Note-se que existe uma diferença considerável entre gasto de capital e gasto corrente. A ideia pode levar ao pensamento de que realizar investimentos em acumulação de capital e ampliar o potencial da economia de fornecer bens e serviços é sempre a melhor opção para a promoção de crescimento econômico. Isso decorre de uma visão deturpada de que os gastos com capital são mais produtivos e os gastos correntes são improdutivos (Divino e Silva Júnior, 2012)

A expansão de gastos com investimentos públicos pode ter um impacto significativo no setor privado. Basicamente porque o investimento possui uma composição de gastos que poderá levar a um crescimento na taxa de retorno do capital, estimulando o investimento com despesas administrativas. Há evidências de que os gastos públicos proporcionam um crescimento no setor privado de quatro a sete vezes maior que os gastos do setor público. Por outro lado, o consumo do governo tem pouca influência positiva na produção (Aschauer, 1989).

Segundo Rocha e Giuberti (2007), Morrison e Schwartz (1991) e Holtz-Eakin (1991), há ligação dos componentes dos gastos públicos em relação ao crescimento econômico, impactando a produtividade do setor privado, corroborando para o crescimento do PIB de países e/ou regiões. Mas as obrigações dependem não apenas da produtividade física dos vários componentes desses gastos, mas também das medidas iniciais em despesas com gastos correntes e evidenciam que uma elevação na participação das despesas correntes tem efeitos de crescimento positivos e estaticamente significativos, como 
colocam Devarajan, Swarrop e Zou (2006). Por outro lado, a relação entre o componente de gasto público de capital e crescimento per capita é negativa, pois os gastos correntes aparentemente produtivos, quando utilizados em excesso, podem se tornar improdutivos. Desse modo, os governos dos países em desenvolvimento têm alocado os dispêndios públicos em favor de gastos de capital em detrimento de gastos correntes.

No caso do Brasil, existem diversas conclusões a despeito da avaliação de investimentos públicos e privados no que diz respeito a composição dos gastos públicos promovendo crescimento econômico. As primeiras pesquisas relacionadas à política fiscal e ao crescimento econômico foram desenvolvidas no intuito de observar o impacto dos gastos agregados sobre o crescimento ou o impacto dos investimentos em infraestrutura, e não no sentido dos efeitos diversos da composição dos gastos públicos sobre o crescimento (Rocha e Gilberti, 2007).

Já no que diz respeito à falta de clareza e informações nos deveres e responsabilidades entre as esferas governamentais, tal situação favorece a repetição e desperdício de recursos para o provimento de bens e serviços. A despeito da Constituição legar aos estados e municípios a realização da grande maioria dos serviços públicos, tais como saúde, educação, saneamento, segurança, etc., a arrecadação de tributos relevantes ficou sob a responsabilidade do Governo Federal. Portanto, existe uma deficiência fiscal em razão de um descompasso entre a arrecadação de receitas e a necessidade de gastos dos estados e municípios. Esse déficit é conhecido como vertical fiscal gap (Boadway e Shah, 2009).

Shah (2006) listou os possíveis elementos que favorecem a criação do vertical fiscal gap: i) disposição indevida de responsabilidades; ii) centralização de poderes tributários; iii) conflitos fiscais entre governos subnacionais; e iv) participação mínima para governos subnacionais na arrecadação de tributos. Assim, o autor coloca que para minimizar esse gap apenas uma redistribuição das responsabilidades, proporcionaria uma descentralização tributária e de transferências intergovernamentais, que foi o método utilizado pelo Brasil para retificar esse efeito.

Portanto, evidencia-se que os municípios têm vários tipos de restrições de ordem fiscal. Mas mesmo convivendo com diversas limitações, os gestores municipais ainda dispõem de uma ampla autonomia para designar os recursos nas diversas áreas de atuação e em vários tipos de despesas. Assim, percebe-se que os municípios devem exercer limites especificados em diversos fundamentos normativos em relação aos gastos públicos e sua composição.

\section{Gastos Públicos em Educação, Saúde e Saneamento Básico}

Em razão de os recursos públicos terem características de condições materiais que possibilitam a formulação e a implementação de políticas públicas, conduzir e avaliar os gastos públicos são funções técnicas/administrativas que os governos devem se comprometer, tais como políticas de gastos voltadas para educação, saúde e saneamento. Isso acontece pois, além dessas características de formulação e implementação, estados 
ainda podem apresentar limites e obstáculos intransponíveis ao fornecimento de demandas sociais, em termos de qualidade e quantidade (Abrahão e Fernandes, 1999).

Rezende (2001) assegura que um novo contexto surge com a redemocratização na Constituição de 1988. Inicia-se um período em que o bordão se torna o resgate da dívida social guardada desde os períodos da ditadura. Institui-se na nação brasileira um clima de expectativas propícias em termos de melhoria dos serviços públicos pelos estados, nas áreas da saúde, previdência, educação, seguro-desemprego, etc., no qual, foi instituída uma lei com crescimento de gastos nessas áreas.

\subsection{Análise dos Gastos Públicos em Educação}

Uma das complexibilidades em se analisar os impactos de dispêndios públicos em educação dá-se pelo fato que estes implicam nas condições de vida daqueles que se educam e também promovem uma série de externalidades sobre o bem-estar daqueles que os rodeiam. Além do mais, os impactos destes investimentos assumem várias formas, como também, várias dimensões. No entanto, estes dispêndios podem ser realizados através de melhorias na qualidade ou na quantidade de educação. Por outro lado, pode-se distinguir se os investimentos em educação em razão com o nível em que ocorrem, sendo capaz de estar correlacionados a uma melhora na educação fundamental, média, superior ou técnica (Barros e Mendonça, 1997). Eles concluíram que investimentos direcionados à área educacional eleva o crescimento da renda per capita dos salários industriais e das exportações por volta de 15 a 30\%, sendo este um efeito estritamente alto sobre o crescimento dos salários industriais e das exportações.

Já para Carvalho (2002), sendo a educação de qualidade quando disponibilizada de forma universal na sociedade, ela transforma o círculo vicioso da pobreza, alicerça o crescimento e entendimento dos direitos civis e políticos. E como coloca Franco (2008), a educação é uma característica importantíssima para o desenvolvimento econômico do País, para o aperfeiçoamento do exercício à democracia e da cidadania, como também o crescimento da expectativa de vida, diminuição da criminalidade e também para a redução da mortalidade infantil.

Atualmente, é bastante aceita a concepção de que uma alta escolaridade média traz para um país, empresas e indivíduos uma maior vantagem comparativa. E, é devido à competitividade crescente entre os países, à intensificação da globalização, às incertezas do futuro e à rápida mudança das bases tecnológicas que a ideia de uma alta escolaridade média colabora para o país ter sua posição favorável no mercado. Mas há quem argumente que o Brasil vem alocando vultosas quantias de recursos humanos e orçamentárias na educação convencional, bem como investindo no déficit da baixa escolaridade média e do analfabetismo da sociedade brasileira de 15 anos ou mais, dentre eles, destacam-se Pena, Albuquerque e Marcio (2012).

Já Zoghbi et al (2009) avaliaram o funcionamento e a eficiência relativa dos estados brasileiros em relação aos gastos que realizam na educação. Gastos em educação dentre os gastos dos governos, aquele que mais colaborariam para proporcionar a alocação de 
recursos e corrigiria algumas falhas de mercado existentes no provimento deste serviço. Além disso, em sua grande maioria, foram considerados mais fomentadores de crescimento do que outros tipos de gastos. A realização de investimentos públicos em educação traria um crescimento ao nível de capital humano, sendo este uma das principais fontes de crescimento econômico de longo prazo, trazendo consigo grandiosos benefícios para a economia. Os autores concluíram que poucos estados apresentaram índice de eficiência do dispêndio público em insumos de educação.

\subsection{Análise dos Gastos Públicos em Saúde}

Uma das complexibilidades em se analisar os impactos de dispêndios públicos em educação dá-se pelo fato que estes implicam nas condições de vida daqueles que se educam e também promovem uma série de externalidades sobre o bem-estar daqueles que os rodeiam. Além do mais, os impactos destes investimentos assumem várias formas, como também, várias dimensões. No entanto, estes dispêndios podem ser realizados através de melhorias na qualidade ou na quantidade de educação. Por outro lado, pode-se distinguir se os investimentos em educação em razão com o nível em que ocorrem, sendo capaz de estar correlacionados a uma melhora na educação fundamental, média, superior ou técnica (Barros e Mendonça, 1997). Eles concluíram que investimentos direcionados à área educacional eleva o crescimento da renda per capita dos salários industriais e das exportações por volta de 15 a $30 \%$, sendo este um efeito estritamente alto sobre o crescimento dos salários industriais e das exportações.

Já para Carvalho (2002), sendo a educação de qualidade quando disponibilizada de forma universal na sociedade, ela transforma o círculo vicioso da pobreza, alicerça o crescimento e entendimento dos direitos civis e políticos. E como coloca Franco (2008), a educação é uma característica importantíssima para o desenvolvimento econômico do País, para o aperfeiçoamento do exercício à democracia e da cidadania, como também o crescimento da expectativa de vida, diminuição da criminalidade e também para a redução da mortalidade infantil.

Atualmente, é bastante aceita a concepção de que uma alta escolaridade média traz para um país, empresas e indivíduos uma maior vantagem comparativa. E, é devido à competitividade crescente entre os países, à intensificação da globalização, às incertezas do futuro e à rápida mudança das bases tecnológicas que a ideia de uma alta escolaridade média colabora para o país ter sua posição favorável no mercado. Mas há quem argumente que o Brasil vem alocando vultosas quantias de recursos humanos e orçamentárias na educação convencional, bem como investindo no déficit da baixa escolaridade média e do analfabetismo da sociedade brasileira de 15 anos ou mais, dentre eles, destacam-se Pena, Albuquerque e Marcio (2012).

Já Zoghbi et al (2009) avaliaram o funcionamento e a eficiência relativa dos estados brasileiros em relação aos gastos que realizam na educação. Gastos em educação dentre os gastos dos governos, aquele que mais colaborariam para proporcionar a alocação de recursos e corrigiria algumas falhas de mercado existentes no provimento deste serviço. 
Além disso, em sua grande maioria, foram considerados mais fomentadores de crescimento do que outros tipos de gastos. A realização de investimentos públicos em educação traria um crescimento ao nível de capital humano, sendo este uma das principais fontes de crescimento econômico de longo prazo, trazendo consigo grandiosos benefícios para a economia. Os autores concluíram que poucos estados apresentaram índice de eficiência do dispêndio público em insumos de educação.

\subsection{Análise dos Gastos Públicos em Saneamento}

A relevância da oferta de serviço público de saneamento básico, tendo em conta sua relação com a saúde pública, trata-se da capacidade administrativa e legislativa dos entes da federação para submeter e realizar esse serviço. Evidenciar o tipo de política nacional de saneamento básico imposto no Brasil, torna-se desejável para debates sobre propostas indicadas para a solvência dos impasses sobre saneamento. Com isso, há uma necessidade de mostrar a carência e a relevância da constituição de um projeto nacional de desenvolvimento, voltado para o saneamento básico. E mais, o saneamento básico não é apenas um ponto sobre infraestrutura, mas envolve também uma questão cultural, social, econômica, desenvolvimentista, ambiental, jurídica e também em respeito aos direitos humanos e a dignidade da pessoa humana (Saker, 2007).

Ademais, é bastante reconhecido e sabido que os serviços de água tratada e de esgoto, em relação à saúde das pessoas, traz um maior bem-estar à sociedade. Sem dúvida, serviços de saneamento básico contêm fortes impactos na saúde da população e no meio ambiente, tendo sido responsáveis pela expressiva redução da mortalidade infantil no Brasil ligada às doenças de propagação hídrica ao longo de décadas (Mendonça e Motta, 2005).

Cunha (2011) afirma que a prestação de serviços como saneamento básico, levando em consideração seu caráter de cadeia industrial para o guarnecimento de bens públicos, como uma rede de fornecimento de serviços públicos designados à efetivação de direitos sociais, vem sofrendo um processo de transformação substancial, desde a aprovação da nova Lei Nacional de Saneamento Básico, em 2007 (Lei Federal no 11.445/2007, doravante denominada LNSB). Porém, algumas dessas mudanças mostraram-se danosas aos objetivos de se aumentar a cobertura desse serviço para as classes de baixa renda da população.

Assim, as tentativas dos governos federal e estadual estão distantes de resguardar o direito ao saneamento básico no País e os entraves são postos em diversas proporções, particularmente a política-ideológica, como a institucional, de financiamento, de gestão, da matriz tecnológica, da participação e controle social, etc. Do mesmo modo, a tradição burocrática da formulação e implementação das políticas públicas no Brasil, o patrimonialismo, as fragilidades do aparato estatal, a corrupção e a retração dos movimentos sociais protestantes na década passada vêm inspirando no avanço de um projeto político social afeiçoado aos princípios de universalidade e de igual para todos (Borja, 2014). 


\section{Estratégia Empírica}

O modelo utilizado tem fundamentação teórica em Barro (1990) e assume que o crescimento econômico de uma economia se dá por meio do fornecimento de bens públicos pelo governo, junto à produção privada de forma endógena. A ideia proposta é que existe uma ligação entre essas despesas e o crescimento do produto com a presença de retornos constantes de escala na acumulação dos fatores produtivos, capital e gastos do governo. Considera-se desnecessário expor o modelo, uma vez que tem sido exaustivamente apresentado na literatura nacional e internacional. Empiricamente, utilizou-se a abordagem metodológica de Bogoni, Hein, Beuren (2011) e Barros (2013), que consideram que gastos públicos apresentam relação positiva com o crescimento econômico municipal.

Os dados são secundários e foram coletados através da Secretaria do Tesouro Nacional (STN) e do Instituto Brasileiro de Geografia e Estatística (IBGE), sendo analisadas as variáveis agregadas sobre dispêndios com educação, saúde, saneamento, habitação, urbanização e cultura. A amostra do estudo abrangeu os 184 dos 185 municípios $^{1}$ do Estado de Pernambuco, com 1472 observações, tendo como período de análise os anos de 2008 a 2015, compreendendo o período no qual as políticas públicas desenvolvimentistas mais atuais estiveram em execução. Os valores monetários foram deflacionados pelo IPCA, com base no ano de 2010.

Utilizou-se um modelo log-log, uma vez que Wooldridge (2016) argumenta que as variáveis monetárias positivas geralmente são transformadas em log, sendo bastante utilizadas na literatura nacional e internacional pela capacidade de suavizar os resultados do modelo exposto. Outra justificativa para o uso de log seria a capacidade de atender a hipótese de normalidade mais facilmente, além de amenizar possíveis problemas de heterocedasticidade e concentração de variáveis estritamente positivas, comum no caso das variáveis de gastos.

Desta forma, a estimação do modelo considerou um painel com a seguinte especificação geral:

$\log (p i b p)_{i t}=\beta_{0}+\beta_{1} \log (g e c p)_{i t}+\beta_{2} \log (g s s p)_{i t}+\beta_{3} \log (g u h p)_{i t}+a_{i}+u_{i t}$

Em que a notação $\log (p i b p)_{i t}$ corresponde à variável dependente, i representa o município, $\mathrm{t}$ diz respeito ao período de tempo; $\beta_{1}$ a $\beta_{3}$ são os parâmetros a serem estimados; $\log (g e c p)_{i t} ; \log (g s s p)_{i t} ; \log (g u h p)_{i t}$ representam as variáveis explicativas. A variável $a_{i}$ capta todos os fatores não observados, constantes no tempo, que afetam $\log$ pibp $_{i t}$. Espera-se valores positivos para $\beta_{1}, \beta_{2}$ e $\beta_{3}$, de acordo com as hipóteses consideras no modelo teórico.

Descrição das variáveis: i) Por pibp compreende-se os valores adicionados brutos dos três grandes setores de atividade econômica - agropecuária, indústria e serviços - bem como os impostos, líquidos de subsídios; ii) gecp refere-se às despesas com ensino fundamental, ensino médio, ensino profissional, ensino superior, educação infantil,

\footnotetext{
${ }^{1}$ Sendo excluído o Município Fernando de Noronha, em razão da ausência de dados sobre gastos públicos.
} 
educação de jovens e adultos, educação especial e outras despesas na função educação, além de despesas com patrimônio cultural, difusão cultural e outras despesas na função cultura; iii) gssp trata das despesas com atenção básica, assistência hospitalar, suporte profilático, vigilância sanitária, vigilância epidemiológica, alimentação e nutrição e outras despesas na função saúde, além de despesas com saneamento básico rural e saneamento básico urbano; iv) por fim, guhp representa as despesas com habitação rural, habitação urbana e outras despesas na função habitação, além de despesas com infraestrutura urbana, serviços urbanos, transportes coletivos urbanos e outras despesas na função urbanismo.

Ainda sobre a escolha do modelo, Wooldridge (2010) destacou que regressão com dados em painel possui vantagens, pois além de aumentar relativamente o tamanho da amostra, ainda possibilita que os graus de liberdade aumentem e diminuam os problemas de colinearidade entre as variáveis explicativas, o que, consequentemente, melhora a qualidade da estimação dos parâmetros. Já Greene (2012) apontou que o benefício principal de utilizar um conjunto de dados em painel sobre uma seção transversal é que ele permitirá ao pesquisador grande flexibilidade na modelagem de diferenças no comportamento entre indivíduos.

\section{Resultados e Discussão}

Observando as estatísticas descritivas das variáveis do estudo, percebe-se que os dispêndios públicos per capita em saúde e saneamento são maiores em relação aos outros gastos. Segundo Barros (2013), a razão pela qual ocorrem maiores gastos na área da saúde e educação seria devido às obrigações legais de percentuais mínimos de gastos nessas áreas que são instituídas pela Constituição Federal, sem os quais estes dispêndios não ocorreriam. Chamam a atenção os desvios-padrão, assinalando as desigualdades regionais presentes no Estado.

Tabela 1. Análise Descritiva das Variáveis

\begin{tabular}{c|c|c|c|c}
\hline \hline Variável & Média & Desv. Padrão & Mínimo & Máximo \\
\hline Produto interno bruto & 7106,581 & 7053,58 & 2589,21 & $128.392,4$ \\
\hline Despesas com educação & 553,335 & 690,617 & 0 & $23.380,88$ \\
\hline Despesas com saúde & 325,354 & 700,874 & 0 & $26.099,8$ \\
\hline Despesas com habitação & 124,605 & 583,639 & 0 & $22.076,16$ \\
\hline N. Obs. & \multicolumn{5}{|c}{1472} \\
\hline N. Grupos & \multicolumn{5}{|c}{184} \\
\hline \hline
\end{tabular}

Os Testes de Hausman e Sargan-Hansen foram utilizados para selecionar entre o modelo de Efeitos Fixos e o de Efeitos Aleatórios. Além dos testes usuais para identificação e correção de possíveis problemas de autocorrelação e heterocedasticidade, comuns em dados de painel. A autocorrelação foi tratada com o teste corretivo de Cochrane-Orcutt e, para amenizar os problemas de heterocedasticidade, as estimações realizadas consideraram erros-padrão robustos. Não existe problema de multicolinearidade entre as variáveis 
consideradas. Os testes de seleção dos modelos indicaram a superioridade da modelagem de Efeitos Fixos relativamente aos dados analisados (Tabela 2).

\section{Tabela 2 - Resultado das Estimações Realizadas para o Modelo de Dados em Painel}

\begin{tabular}{|c|c|c|c|}
\hline Variáveis & $\begin{array}{c}\text { Dados } \\
\text { Empilhados } \\
(\text { Pools }) \\
\end{array}$ & $\begin{array}{c}\text { Efeito } \\
\text { Aleatório } \\
\text { (RE) } \\
\end{array}$ & $\begin{array}{c}\text { Efeito } \\
\text { fixo } \\
\text { (FE) } \\
\end{array}$ \\
\hline \multicolumn{4}{|l|}{ In produto interno bruto } \\
\hline ln despesas com educação & $\begin{array}{c}-0,163 * * \\
(0,076)\end{array}$ & $\begin{array}{c}0,321 * * * \\
(0,044)\end{array}$ & $\begin{array}{c}0,368 * * * \\
(0,045)\end{array}$ \\
\hline ln despesas com saúde & $\begin{array}{c}0,201 * * * \\
(0,068)\end{array}$ & $\begin{array}{c}0,029 \\
(0,023)\end{array}$ & $\begin{array}{c}0,014 \\
(0,023)\end{array}$ \\
\hline ln despesas com habitação & $\begin{array}{c}0,096 * * * \\
(0,032)\end{array}$ & $\begin{array}{l}-0,200^{*} \\
(0,011)\end{array}$ & $\begin{array}{c}-0,033 * * \\
(0,013)\end{array}$ \\
\hline _cons & $\begin{array}{c}8,164 * * * \\
(0,356)\end{array}$ & $\begin{array}{c}6,638 * * * \\
(0,290)\end{array}$ & $\begin{array}{c}6,492 * * * \\
(0,289)\end{array}$ \\
\hline dummies & & & $N S$ \\
\hline Estatística-F/Wald & $6,37 * * *$ & $67,19 * * *$ & $27,53 * * *$ \\
\hline $\mathrm{R}^{2}$ & 0,0816 & & \\
\hline $\mathrm{R}^{2}-$ within & & 0,3091 & 0.3108 \\
\hline $\mathrm{R}^{2}-$ between & & 0,0661 & 0,0788 \\
\hline $\mathrm{R}^{2}-$ overall & & 0,0035 & 0,0014 \\
\hline $\begin{array}{l}\text { Teste de } \\
\text { Breusch Pagan }\end{array}$ & \multicolumn{3}{|c|}{$2411,77 * * *$} \\
\hline Teste de Hausman & \multicolumn{3}{|c|}{$2.591,30 * * *$} \\
\hline Teste de Sargan-Hansen & \multicolumn{3}{|c|}{$97,56 * * *$} \\
\hline N. Observações & 1425 & 1425 & 1425 \\
\hline N. Grupos & & 184 & 184 \\
\hline
\end{tabular}

Nota. 1) Entre parênteses encontram-se os erros-robustos); 2) Níveis de significância: ***: significativo a $1 \%$; **: Significativo a $5 \%$; * Significativo a $10 \%$.

De acordo com os resultados obtidos no modelo de Efeitos Fixos, os gastos per capita em educação mostraram-se relacionados com o crescimento econômico dos municípios pernambucanos no período analisado, apresentando os sinais esperados na literatura. Assim, a cada 1\% das receitas municipais gastas nas áreas da educação e cultura, geraram um crescimento econômico nos municípios de 36,8\%, sendo este crescimento significante ao nível de significância de $1 \%$. Este resultado corrobora com diversos estudos encontrados na literatura nacional e internacional.

No estudo de Morais, Araújo e Monteiro (2012) sobre gastos públicos impactando no crescimento econômico dos municípios cearenses, os autores revelaram que os gastos em capital humano eram os que mais promoviam crescimento econômico nos municípios em relação ao capital físico. Desse modo, os gastos públicos direcionados ao aumento da educação estariam relacionados ao crescimento do produto, o que sugere que os gastos em capital humano sejam mais efetivos para estimular a economia e gerar crescimento. Esses 
resultados também foram verificados por Devarajan, Swarrop e Zou (2006), ao apontarem o capital humano como uma variável importantíssima para o crescimento econômico.

Já os gastos públicos per capita em saúde e saneamento básico só se mostraram significantes a nível de $10 \%$ no modelo sem erros-robustos. Ao considerar, todavia, o modelo com erros-robustos para reduzir vieses relacionados à heterocedasticidade presente nos dados, a variável não passou no teste de significância. Como visto na Introdução deste trabalho, a literatura internacional considera vários elementos ao relacionar gastos públicos e crescimento econômico. Talvez aspectos como qualidade institucional (Arora e Chong, 2018) possam ser um entrave para a significância desta variável no Estado de Pernambucano.

De todo modo, Cruz, Teixeira e Braga (2010) reafirmaram a importância de gastos públicos como facilitador do acesso a bens e serviços, tais como água potável, dieta equilibrada, cuidados médicos, que consequentemente garantem saúde e longevidade aos indivíduos. Ademais, boas condições de saúde favoreceriam a promoção do crescimento econômico, gerando transbordamentos positivos ao crescimento econômico no longo prazo. Nesse sentido, talvez um modelo dinâmico possa captar este efeito positivo, dado que neste estudo essa evidência não foi encontrada.

É extensa a literatura que revela os efeitos positivos dos gastos com saúde sobre o crescimento econômico e não se pretende argumentar em contrário. O estudo de Mendonça e Motta (2005) apontou a relevância dos serviços de água tratada e esgoto para a saúde da população e consequente impacto no fomento do crescimento econômico da economia. Todavia, há que se recordar que o Brasil, como país continental, tem diferenças estruturais e institucionais entre as unidades de federação, havendo certamente heterogeneidade nos impactos dos gastos nos diferentes estados federativos, tal como ocorre entre os países, como foi colocado por Ahlborn e Schweickert (2016) e Beckmann, Endrich e Schweickert (2016).

Já os gastos per capita nas áreas de urbanização e habitação indicaram correlação negativa com o crescimento econômico dos municípios pernambucanos. Causa estranhamento o sinal negativo encontrado neste estudo, mesmo com a indicação de Bender Filho (2019) de que aumentar gastos indiscriminadamente não aumenta, necessariamente, o crescimento econômico, sendo, portanto, natural que algumas variáveis não encontrem significância estatística no modelo.

Ademais, trabalhos nacionais reforçam a tese de que esta variável não impactaria no crescimento econômico, pelo menos em análises de curto prazo. Nesse sentido, o trabalho de Tarda e Rodrigues (2015) indicou que os gastos em educação seriam mais fomentadores para a promoção do crescimento econômico do que os gastos com urbanismo. Também Rocha e Giubert (2007) já haviam apontado para a hipótese de que esses gastos não influenciariam o crescimento econômico dos municípios.

Analisando as dummies municipais, dentre os 183 municípios considerados (excluindo Xexéu para referência), apenas Araçoiaba, Bodocó, Brejo da Madre de Deus, Carnaíba, Carnaubeira da Penha, Jaqueira, Jurema, Saloá e Solidão não foram 
significativas. Ressalte-se que estes municípios são muito pequenos e apresentam baixo PIB per capita.

Alguns exercícios foram realizados com o objetivo de observar a robustez dos resultados. Nesse sentido, foram realizadas estimativas com sub amostras, tanto considerando o corte dos municípios com PIB per capita mais baixos, como retirando da amostra municípios com PIB per capita mais altos. Em essência os modelos não se alteraram quanto a significância das variáveis e sinais encontrados, a não ser no modelo de dados empilhados. Contudo, houve alteração significativa na significância das dummies, o que era esperado, uma vez que a amostra foi modificada nestes casos.

\section{Considerações Finais}

Este artigo procurou contribuir com a discussão sobre a relação existente entre os gastos públicos e o crescimento econômico, utilizando o recorte dos municípios pernambucanos no período de 2008 a 2015, e tendo como o principal objetivo a análise das variáveis explicativas decompostas em gastos públicos nas áreas da educação, cultura, saúde, saneamento, habitação e urbanismo. Portanto, a hipótese levantada no estudo relacionou os gastos públicos municipais ao aumento no PIB dos municípios considerados. Mas esta hipótese só foi corroborada para os gastos com educação, indiscutivelmente essenciais para o crescimento e desenvolvimento das sociedades modernas.

Ditos importantes pela sociedade e corroborados na Carta Magna do País, os gastos com educação e saúde são naturalmente apontados como importantes elementos na construção de maior crescimento econômico dos municípios, quando comparados com outras variáveis de dispêndios públicos. Seguramente, em tempos de crise e necessidade de ajustes fiscais, passam também a ser questionados por grupos que estão no governo e buscam enxugar as contas públicas.

Todavia, a vasta literatura nacional e internacional sobre gastos públicos e crescimento econômico tem, cada vez mais, colocado em xeque estas relações lineares entre os déficits públicos e aumento do produto interno, sendo colocadas questões de ordem institucional, de governança, geográficas, culturais, políticas, como elementos também importantes na construção deste resultado de maior crescimento esperado.

Não se pretende com isto refutar a hipótese de que gastos com serviços essenciais, tais como educação, saúde, moradia e urbanismo, não levem a maior nível de crescimento econômico das regiões. Mas se faz necessário que se amplie o debate, incorporando aos modelos questões complementares, mas essenciais a cada localidade e que poderão definir a qualidade dos gastos e seus efeitos sobre as economias.

Além disso, a garantia de condições básicas de saúde e saneamento, habitação e urbanismo para a população aumenta o bem-estar da sociedade e pode contribuir com a produtividade dos municípios. Entretanto, esta relação não foi evidenciada neste estudo. Deduz-se, portanto, que os elementos supracitados possam ser importantes para revelar este efeito. 
Ademais, sugere-se para estudos futuros a averiguação destas relações com modelos dinâmicos, o que levará a necessidade de um painel longo, mas que possibilitará análises de longo prazo, de onde se imagina que estas relações possam ser verificadas.

\section{Referências}

ABRAHÃO, J.; FERNANDES, M. A. C. Sistema de Informações sobre os Gastos Públicos da Área de Educação - SIGPE: Diagnóstico para 1995. Instituto de pesquisa econômica aplicada-IPEA. Brasília, 1999. p. 42. Texto para discussão No 674.

AHLBORN, M.; SCHWEICKERT, R. Public Debt and Economic Growth - Economia Systems Matter. CEGE, Discussion Papers, n.281, 2016.

ARORA, P.; CHONG, A. Government Effectiveness in the Provision of Public Goods: the role of institutional quality. Journal of Applied Economics, v.21, n.1, 175-196, 2018. DOI: https://doi.org/10.1080/15140326.2018.1550593.

ARRAES, R.A.; TELES, V. K. Política Fiscal e Crescimento Econômico: Aspectos Teóricos e Evidências Empíricas para as Regiões Brasileiras. Revista Econômica do Nordeste, Fortaleza, v. 32, n. Especial p. 676-690, 2001.

ASCHAUER, D. Is Public Expenditure Productive? Journal of Monetary Economics, 23:177-200, 1989. DOI: https://doi.org/10.1016/0304-3932(89)90047-0.

BARRO, R.J. Government Spending in a Simple Model of Endogenous Growth. Journal of Political Economy, v. 98, p. 103-125, 1990. DOI: https://doi.org/10.1086/261726.

BARROS, N.A.L.R. Evidências Empíricas sobre a Relação entre Formação do PIB e Gastos Públicos nos Municípios Pernambucanos no Período de 1997 a 2009. 2013. 105 f. Dissertação (Mestrado) - Universidade Federal de Pernambuco, CAA, Programa de Pós-Graduação em Economia.

BARROS, R. P. de.; MENDONÇA, R. Investimentos em Educação e Desenvolvimento Econômico. Instituto de Pesquisa Econômica Aplicada. Rio de Janeiro, 1997. Texto para Discussão $\mathbf{N}^{\circ} 525$.

BECKMANN, J.; ENDRICHS, M.; SCHWEICKERT, R. Government Activity and Economic Growth - one size fits All? Int Econ Econ Policy, 13:429-450, 2016.

BENDER FILHO, R. Gasto Público e Crescimento Econômico: Testando a Hipótese de Wagner à Economia Brasileira. Planejamento e Políticas Públicas, n.53, jul./dez., 2019.

BRASIL. Lei Complementar nº 101, de 4 de maio de 2000. Estabelece normas de finanças públicas voltadas para a responsabilidade na gestão fiscal e dá outras providências. Diário Oficial [da] República Federativa do Brasil, Brasília, DF, 5 maio de 2000 . 
BOADWAY, R.; SHAH, A. Fiscal Federalism: principles and practice of multiorder governance. New York: Cambridge University Press, 2009.

BOGONI, N.M.; HEIN, N.; BEUREN, I.M. Análise da Relação entre Crescimento Econômico e Gastos Públicos nas Maiores Cidades da Região Sul do Brasil. Revista de Administração Pública, Rio de Janeiro, n. 45(1), p. 159-179, jan/fev 2011.

BORJA, P. C. Política Pública de Saneamento Básico: uma análise da recente experiência brasileira. Saúde Soc. São Paulo, v.23, n.2, p.432-447, 2014.

BRASIL. Lei Complementar $n^{\circ} 101$, de 4 de maio de 2000. Estabelece normas de finanças públicas voltadas para a responsabilidade na gestão fiscal e dá outras providências. Diário Oficial [da] República Federativa do Brasil, Brasília, DF, 5 maio de 2000 .

BUTKIEWICZ, J.L.; YANIKKAYA, H. Institutions and the Impact of Government Spending on Growth. Journal of Applied Economics, v.14, n.2, 319-341, nov. 2011. DOI: https://doi.org/10.1016/S1514-0326(11)60017-2.

CÂNDIDO JUNIOR, J. O. C. Os Gastos Públicos no Brasil são Produtivos? Planejamento de políticas públicas ppp, n. 23, p. 234-260, junho 2001.

CARVALHO, M. d. Cidadania no Brasil: o longo caminho. edição edn, Rio de Janeiro: Civilização Brasileira, 2002.

CORREIA, F. M.; NEDUZIAK, L. C. R. Alocação dos Gastos Públicos e Crescimento Econômico: um estudo em painel para os Estados brasileiros. Revista de Administração Pública, Rio de Janeiro, 51(4):616-632, jul. - ago. 2017.

CUNHA, A.S. Saneamento Básico no Brasil: Desenho Institucional e Desafios Federativos. Rio de Janeiro: IPEA, 2011. Texto para Discussão, n. 1565.

CUNHA, C. G. S. da. Avaliação de políticas públicas e programas governamentais: tendências recentes e experiências no Brasil. Secretaria de Coordenação e Planejamento/RS, 2006. Disponível em: < http:// http://www.ufpa.br/epdir/images/docs /paper06.pdf > . Acesso em: 08/08/18.

CRUZ, A. C.; TEIXEIRA, E. C.; BRAGA, M. J. Os Efeitos dos Gastos Públicos em Infraestrutura e em Capital Humano no Crescimento Econômico e na Redução da Pobreza no Brasil. EconomiA, Selecta, Brasília (DF), v.11, n.4, 163-185, dez. 2010.

DEVARAJAN, S.; SWARROP, V.; ZOU, H. The composition of public expenditure and economic growth. Journal of Monetary Economics, v. 37, p. 313-344, 1996.

DOI: https://doi.org/10.1016/S0304-3932(96)90039-2

DIVINO, J. A.; SILVA JUNIOR, R. L. S. da. Composição dos Gastos Públicos e Crescimento Econômico dos Municípios Brasileiros. Revista Economia, Brasília, v.13, n.3a, p.507-528, set/dez 2012. 
FRANCO, A.M. P. Os Determinantes da Qualidade da Educação no Brasil. Tese Doutorado em Economia - Universidade de São Paulo, SP, 2008.

FROTA, I.L.N. Evolução Recente da Economia Pernambucana: as políticas em curso e seus impactos no crescimento do Estado. 2013. 232 p. Tese (Doutorado) Universidade Federal de Pernambuco. CCSA. Economia, Recife.

GREENE, W.H. Econometric Analysis. Prentice Hall, 2012.

HOLTZ-EAKIN, D. Public-sector Capital and the Productivity Puzzle. Syracuse, NY: Syracuse University, 1991. Mimeo. DOI: https://doi.org/10.3386/w4122.

MACEDO, J. J.; CORBARI, E. C. Efeitos da Lei de Responsabilidade Fiscal no Endividamento dos Municípios Brasileiros: uma análise de dados em painéis. Revista Contabilidade \& Finanças, v. 20, n. 51, p. 44-60, set./dez., 2009.

DOI: http://dx.doi.org/10.1590/S1519-70772009000300004

MASSAMBANI, M. O. Avaliação Econômica dos Gastos com Saúde Pública dos Principais Municípios Paranaenses. Dissertação (Programa de Pós-Graduação em Economia Regional) - Universidade Estadual de Londrina, Londrina, 2013.

MATIAS-PEREIRA, J. Curso de Administração Pública: Foco nas instituições e ações governamentais / José Matias-Pereira. - 2. ed. - São Paulo: Atlas, 2009.

MENDONÇA, M.J.C.; MOTTA, R.S. Saúde e Saneamento no Brasil. Rio de Janeiro: IPEA, 2005. Texto para Discussão, n⿳ 1081.

MENICUCCI, T. M. G. A Política de Saúde no Governo Lula. Saúde Soc. São Paulo, v.20, n.2, p.522-532, 2011. DOI: http://dx.doi.org/10.1590/S0104-12902011000200022

MORAIS, G. S.; ARAUJO, J. A. de.; MONTEIRO, V. B. Gastos Públicos e Crescimento Econômico: evidências da economia cearense. Economia Ceará em Debate 2012, Fortaleza, v. 1, p. 57-75, 2013.

MORRISON, C.; SCHWARTZ, A. E. State Infrastructure and Productive Performance. Medford, MA: Tufts University, 1991. Mimeo.

DOI: https://doi.org/ 10.3386/w3981.

PAIM, J. et al O sistema de saúde brasileiro: história, avanços e desafios. Saúde no Brasil v. n. 1 p. 1-21, 2011.

PAPARAS, D.; RICHTER, C.; KOSTAKIS, I. The Validity of Wagner's Law in the United Kingdom During the Last Two Centuries. Int Econ Econ Policy. Published Online: 20 June 2018. DOI: https://doi.org/10.1007/s10368-018-0417-7 
PENA, C. R.; ALBUQUERQUE, P. H. M.; MARCIO, C. J. A Eficiência dos Gastos Públicos em Educação: evidências georreferenciadas nos municípios goianos. Economia Aplicada, v. 16, n. 3, 2012, p. 421-443.

DOI: https://doi.org/10.1590/S1413-80502012000300004

REZENDE, F. Finanças Públicas. 2.ed. São Paulo: Atlas, 2001.

RODRIGUES, R.V.; TEIXEIRA, E.C. Gasto Público e Crescimento Econômico no Brasil: uma análise comparativa dos gastos das esferas do Governo. Revista Brasileira de Economia, v. 64, n. 4, p. 423-438, 2010.

DOI: https://doi.org/10.1590/S0034-71402010000400005

RIANI, F. Economia do Setor Público: uma abordagem introdutória. 4.ed. São Paulo: Atlas, 2002.

ROCHA, F.; GIUBERTI, A. C. Composição do Gasto Público e Crescimento Econômico: uma avaliação macroeconômica da qualidade dos gastos dos Estados brasileiros. Economia Aplicada, São Paulo, v. 11, n. 4, p. 463-485, 2007.

DOI: https://doi.org/10.1590/S1413-80502007000400001

SAKER, J.P.P. Saneamento Básico e Desenvolvimento. 2007. 145 p. Dissertação (Mestrado em Direito Político e Econômico) - Universidade Presbiteriana, São Paulo.

SANTOS, A. C. G. do. E.; FERNANDO, V. C. N.; BEZERRA, A. F. B. Despesa Pública Municipal com Saúde em Pernambuco, Brasil de 2000 a 2007. Ciência \& Saúde Coletiva, 17(4):861-871, 2012. DOI: https://doi.org/10.1590/S1413-81232012000400009

SHAH, A.A. Practitioner's Guide to Intergovernmental Fiscal Transfers. World Bank Policy Research Working Paper, n. 4039, 2006.

SILVA, S. S.; TRICHES, D. Uma Nota sobre Efeitos de Gastos Públicos Federais sobre o Crescimento Econômico da Economia Brasileira. Revista Brasileira de Economia, Rio de Janeiro v. 68 n. 4 / p. 547-559 Out-Dez 2014.

DOI: https://doi.org/10.1590/S0034-71402014000400006

SOUKIAZIS, E.; ANTUNES, M.; KOSTAKIS, I. The Greek Economy Under the TwinDeficit Pressure: a demand orientated growth approach. International Review of Applied Economics. Published online: 04 Jul 2017.

DOI: https://doi.org/10.1080/02692171.2017.1338678.

TARDA, R. B.; RODRIGUES, R. V. A Influência dos Gastos em Educação no Crescimento Econômico da Região Administrativa de Campinas. Estudo \& Debate, Lajeado, v. 22, n. 2, p. 07-31, 2015.

TEIXEIRA, H.V.; BARROSO, V. G. Gasto Público com Saúde no Brasil: possibilidades e desafios. In: Anais da I Jornada de Economia da Saúde, 20 e 21 de novembro de 2003, São Leopoldo, RS. ABRES/UNISINOS, 2003. 
WOOLDRIDGE, J.M. Introdução à Econometria: uma abordagem moderna. São Paulo, 2016.

ZOGHBI, A. C. P.; ROCHA, F. F.; MATOS, E. H. C. de.; ARVATE, P. R. Mensurando o Desempenho e a Eficiência dos Gastos Estaduais em Educação Fundamental e Média. Estudos Econômicos, São Paulo, v. 39, n. 4, p. 785-809, 2009.

DOI: https://doi.org/10.1590/S0101-41612009000400004

ZUCCHI, P.; NERO, C. D.; MALIK, A. M. Gastos Em Saúde: Os Fatores Que Agem Na Demanda E Na Oferta Dos Serviços De Saúde. Saúde e Sociedade. v.9 n.1-2 p. 127-150, 2000. DOI: https://doi.org/10.1590/S0104-12902000000100010 